\title{
Posture and discomfort assessment in computer users while using touch screen device as compared with mouse-keyboard and touch pad-keyboard
}

\author{
N. Kargar ${ }^{\mathrm{a}}$, A.R. Choobineh ${ }^{\mathrm{b}, *}$, M. Razeghic ${ }^{\mathrm{c}}$, S. Keshavarzi $^{\mathrm{d}}$ and N. Meftahic \\ ${ }^{a}$ Department of Ergonomics, School of Health, Shiraz University of Medical Sciences, Shiraz, Iran \\ ${ }^{\mathrm{b}}$ Research Center for Health Sciences, Institute of Health, Shiraz University of Medical Sciences, Shiraz, Iran \\ ${ }^{\mathrm{c}}$ Department of Rehabilitation, School of Rehabilitation Sciences, Shiraz University of Medical Sciences, \\ Shiraz, Iran \\ ${ }^{\mathrm{d}}$ Department of Epidemiology, School of Health, Shiraz University of Medical Sciences, Shiraz, Iran
}

Received 6 November 2016

Accepted 13 July 2017

\begin{abstract}
.
BACKGROUND: Touch screen computers require significant arm and hand movements. This can result to body discomfort and biomechanical load in users.

OBJECTIVES: This study was carried out to examine posture and users' discomfort while using touch screen device as compared with mouse-keyboard and touch pad-keyboard.

METHODS: Twenty three (23) students participated in this experimental study. The subjects completed pre-defined tasks in three $15 \mathrm{~min}$ trials by means of touch screen, touch pad-keyboard and mouse-keyboard as input devices. Postural angles were measured by Qualisys motion capture system. Body discomfort was assessed by a 10-cm visual analog scale. Rating scale was employed to assess the perception of subjects on the posture of body parts while utilizing the three devices.

RESULTS: There was no significant difference in head inclination when using the three types of devices. Nevertheless, the mean of neck $(p=0.005)$ and trunk $(p<0.0001)$ inclinations as well as arm angle $(p<0.0001)$ while using touch screen, differed significantly from the two other devices and were more deviated from neutral posture. The type of input device was found to have significant effect on the right shoulder $(p=0.017)$, right elbow $(p=0.031)$, right wrist/hand $(p=0.004)$ and whole body discomfort $(p=0.026)$. Touch screen caused more discomfort in the mentioned regions when compared to the other two devices. Friedman test showed that differences of mean ratings for perceived shoulder and elbow postures in the 3 trials were significant ( $p=0.005$ and $p=0.011$, respectively). Touch screen was the most unfavorable input device based on the subjects' judgment.
\end{abstract}

CONCLUSION: Touch screen caused more deviated postural angles, increased body discomfort and unfavorable postures.

Keywords: Motion analysis, data entry device, postural angles

\section{Introduction}

*Address for correspondence: A.R. Choobineh, Research Center for Health Sciences, Institute of Health, Shiraz University of Medical Sciences, Shiraz, Iran. P.O. Box: 71645-111, Shiraz, Iran. Tel.: +0098 917118 4450; Fax: +0098 713 7260225; E-mail: alrchoobin@sums.ac.ir.

The increasing presence of notebook computers may be the logical solution to the lack of space and high worker density in various work areas. Furthermore, the compact design of notebook computer 
makes it more attractive than desktop computers [1]. Extended use of conventional computer input devices is associated with negative musculoskeletal outcomes [2]. The technology development and appearance of touch screen device seem to overcome disadvantages of other types of computer input devices with the aim of reducing the physical load imposed by them [3]. Despite low physical demand and energy expenditure during the use of computers, static body posture is the main musculoskeletal risk factor for computer users. Some studies revealed the relevance between static trapezius muscle posture and neck-shoulder disorders [4-8]. Although the use of computer desktop with touch screen has not yet been wildly raised $[6,8]$, the occurrence of musculoskeletal disorders in the neck and upper limb have dramatically increased in recent years as a result of work station design [9]. Touch screen computers require significant arm and hand movement, thus leading to body discomfort and biomechanical load in users. According to a hypothesis in a previous study, as the user's comfort decreases, the head and neck posture lean more while using touch screen [10].

Given the above, since there are few studies specifically related to the comparison of touch screen with other types of computer input devices from the viewpoint of users' posture and discomfort, the present study was carried out to assess users' posture and discomfort while using touch screen in comparison to two other data entry devices i.e., mouse-keyboard and touch pad-keyboard. It is believed that the results of this study can be an appropriate basis for testing this hypothesis that, using touch screen may deteriorate working postures of different body regions and increases users' discomfort. In addition, this comparison can help in determining which of these computer input devices are to be suggested.

\section{Materials and methods}

\subsection{Subjects}

In this experimental study, 23 right-handed students (11 females and 12 males) of Shiraz University of Medical Sciences (SUMS), Shiraz, Iran, with normal eyesight with no history of musculoskeletal disorders participated voluntarily. The study was carried out in accordance with the Helsinki Declaration of 1964 as revised in 2008 [11]. All participants signed an informed consent form prior to the commencement of this study. The study was reviewed and approved by the ethics committee of the Shiraz University of Medical Sciences.

\subsection{Experiment procedure and conditions}

For each subject, the experiment comprised 3 trials performed under controlled laboratory conditions. In each trial, the subjects carried out pre-defined standard tasks (copying and pasting pictures and typing in Word environment and dragging the pictures to the desktop environment) employing one of the three input devices i.e., touch screen, touch pad-keyboard and mouse-keyboard. Each trial lasted $15 \mathrm{~min}$ followed by a break of $10 \mathrm{~min}$. To make our study comparable with the previous ones, the task duration was chosen the same as previous studies [9]. The sets of trials were presented in random order to counterbalance the carry-over and order effects of experiments. Before the experiment, each subject was familiarized with the tests and had enough practice working with laptop and learn the tasks and also adjusted her/his workstation (the height of the seat and the distance between the seat and the table). This adjustment was then kept constant during the experiment.

Figure 1 illustrates the workstation in which the experiment was conducted. As displayed, the workstation consisted of a table, an adjustable chair and a foot rest in case it was required. An ASUS laptop computer (S300CA) with touch screen (13.3 inches) and a standard mouse were utilized to carry out the tasks. Illumination on the working table was measured to be approximately 250 lux in all 3 trials.

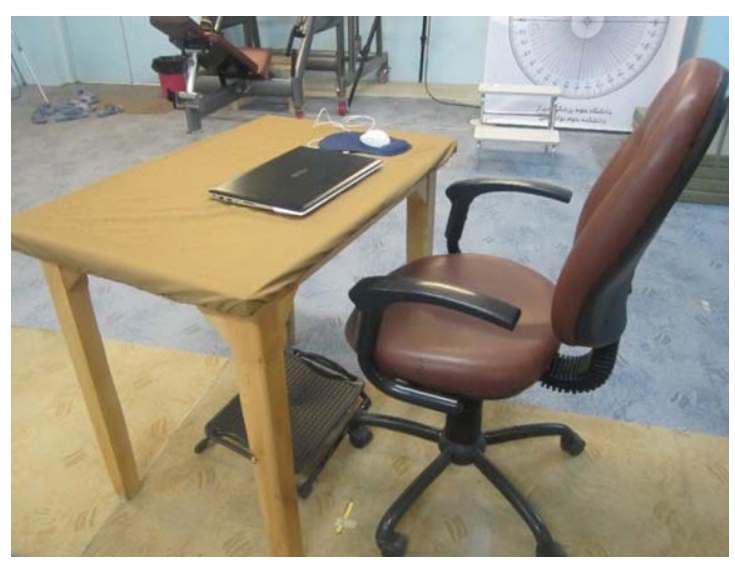

Fig. 1. The experimental workstation. 


\subsubsection{Measurement of variables}

A) Posture measurement was carried out by Qualisys three dimensional (3D) motion capture system based on optical markers, made in Sweden. Reflective polystyrene coated markers were placed at the eye (outer canthus), the ear (tragus), the neck (C7), the hip (greater trochanter), the shoulder (greater tubercle), the elbow (lateral humeral epicondyle), and the wrist (styloid process of ulna) of the subjects (Fig. 2). The markers were put on the right side of the body, as a result of the dominant role of the right hand among the study subjects. The marker positions were determined via Qualisys system during the pre-defined standard tasks at each trial, and while the subjects were in a neutral posture (sitting upright, symmetric with respect to the sagittal plane, looking straight ahead along the horizontal line, arms hanging down along the trunk, forearms perpendicular to the upper arms). On the basis of the marker positions, the following dependent variables were measured (Fig. 2):

- Head inclination (HI), defined as the angle between the horizontal and the line through

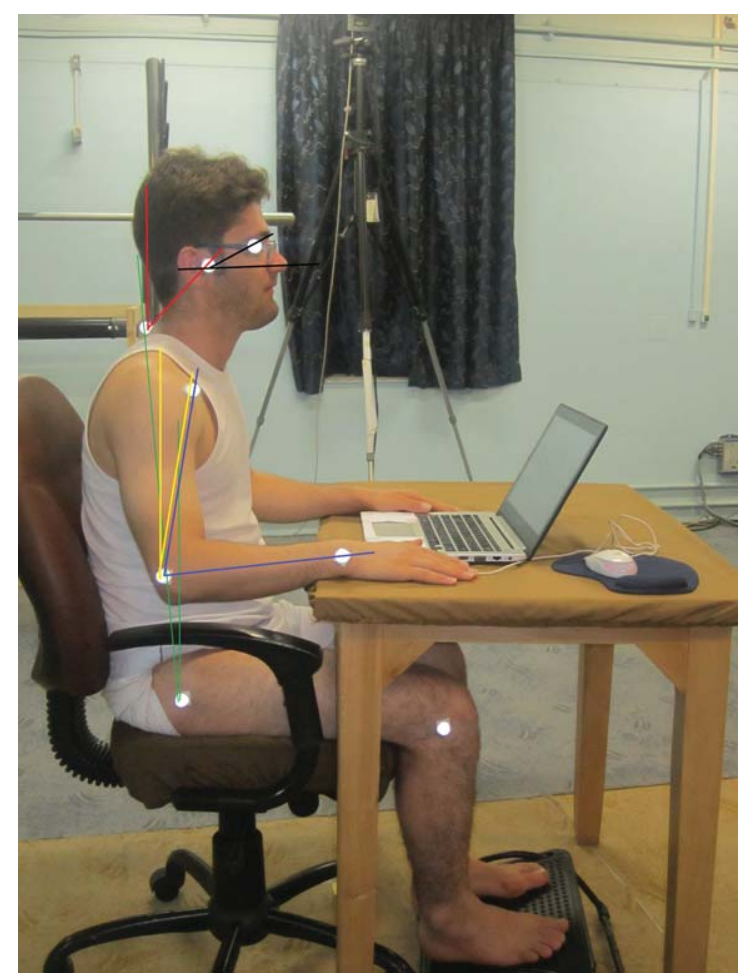

Fig. 2. Positions of markers placed on the defined landmarks. Head Inclination (black bisectors), Neck Inclination (red bisectors), Trunk Inclination (green bisectors), Arm Angle (yellow bisectors), and Elbow Angle (blue bisectors). the markers at the eye and the ear. A negative value indicates that the head is inclined forwards $[11,12]$.

- Neck inclination (NI), defined as the angle between the vertical and the line through the markers at the ear and the neck. A negative value implies that the neck is inclined backwards $[12,13]$.

- Trunk inclination (TI), defined as the angle between the vertical and the line through the markers at the neck and the hip. A negative value indicates that the trunk is inclined backwards [14].

- Arm angle (AA), defined as the angle between the vertical and the line through the markers at the shoulder and the elbow. A negative value indicates arm extension [15-17].

- Elbow angle (EA), defined as the angle between the line through the markers at the shoulder, the elbow and the line through the markers at the elbow and the wrist [18-20].

There were three 15-minute trials for each subject. So, all three trials lasted 45 minutes. In each trial, the subject carried out the pre-defined tasks for 15 minutes. The postural angles were calculated in the first (0-1), middle (7-8) and the last (14-15) minutes of each trial. The deviation of postural angles from the neutral (reference) posture was employed to compare the results of the 3 trials. Figure 3 illustrates a participant performing the pre-defined tasks at the experimental workstation.

Qualisys motion capture system can capture the angles in three $\mathrm{XY}, \mathrm{YZ}$ and $\mathrm{XZ}$ axes. In this study, the postural angles were measured in sagittal plane (YZ axis).

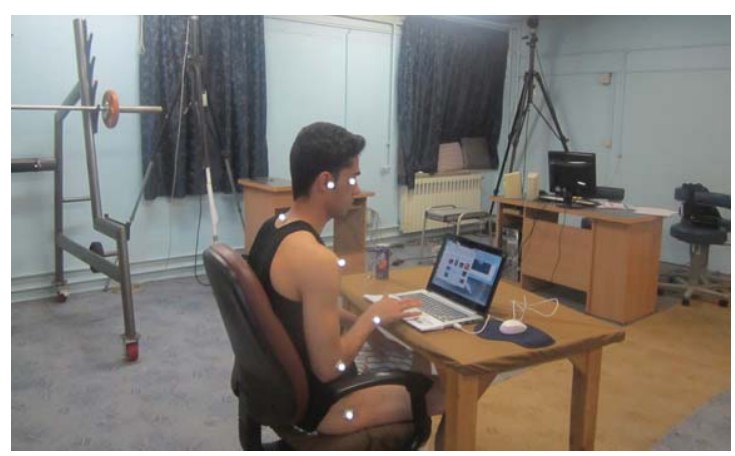

Fig. 3. A subject is performing the tasks at the experimental workstation. 
B) Users' perceptions were recorded by a questionnaire containing 2 modules (rating techniques).

- Localized postural discomfort: The subject was asked to rate her/his postural discomfort in 5 body regions including neck, back, shoulders, elbows, and wrist/hand illustrated on a diagram of the rear view of a human body, employing a visual numeric rating scale $[11,21]$ ranging from 0 (no discomfort) to 9 (very severe discomfort). A written response was given at the end of each trial. An overall dependent variable was also constructed, i.e. postural discomfort of the whole body by summing the resulting scores for all 5 body regions divided by 5 . It is believed that this variable provide reliable results for comparison of conditions, such as in the present study [22].

- Perceived posture: The subject was asked to rate her/his perception of the posture of neck, back, right shoulder and right elbow. Soon after the trial, a written response was given on a sevenpoint scale $(1=$ very favorable, $3=$ favorable, $5=$ unfavorable, $7=$ very unfavorable). For intermediate responses, scores of 2, 4 and 6 were available).

\subsection{Data analysis}

Using Kolmogorov-Smirnov test it was determined that the data were non-parametric. The effects of the input device type on postural variables, in addition to the variables relating to localized postural discomfort were tested by Analysis of Variance (ANOVA) for Repeated Measures. Differences between sets of experimental conditions were tested utilizing pairwise Comparisons Test. The effect of the input device type on perceived posture was examined by Friedman test [23]. Differences between sets of experimental conditions were tested by Wilcoxon analysis [24]. The level of statistical significance in all tests was set at $\alpha=0.05$. The data analyses were carried out using SPSS software (Version 19).

\section{Results}

Table 1 shows some personal details of the participants. Eight subjects (35\%) were undergraduates and 15 individuals $(65 \%)$ were postgraduate students. Two of them were married and 21 of them were single.

\subsection{Postural variables}

The results of postural angles measurement in the 3 experimental conditions are shown in Table 2. The values presented in this table indicate the average amount of deviation of each postural angle from the neutral posture in the test subjects. Regarding this, in each case, the closer a value to zero, the more appropriate the posture adapted by the subject. Table 3 presents the results of pairwise comparisons between the 3 input devices.

Table 1

Some personal details of the participants

\begin{tabular}{|c|c|c|c|c|c|c|c|c|c|}
\hline \multirow[t]{2}{*}{ Personal characteristics } & \multicolumn{3}{|c|}{ Female $(n=11)$} & \multicolumn{3}{|c|}{ Male $(n=12)$} & \multicolumn{3}{|c|}{ All $(n=23)$} \\
\hline & $\mathrm{M}^{\mathrm{a}}$ & $\mathrm{SD}^{\mathrm{b}}$ & Range & $\mathrm{M}^{\mathrm{a}}$ & $\mathrm{SD}^{\mathrm{b}}$ & Range & $\mathrm{M}^{\mathrm{a}}$ & $\mathrm{SD}^{\mathrm{b}}$ & Range \\
\hline Age (year) & 27.55 & 2.73 & $22-30$ & 23.5 & 2.54 & $20-27$ & 25.43 & 3.30 & $20-30$ \\
\hline Height $(\mathrm{cm})$ & 163.18 & 4.87 & $155-170$ & 176.75 & 5.45 & $163-183$ & 170.26 & 8.58 & $155-183$ \\
\hline Weight $(\mathrm{kg})$ & 63.91 & 7.59 & $57-80$ & 68.58 & 9.00 & $53-85$ & 66.35 & 8.51 & $53-85$ \\
\hline Working with computer (hour/day) & 4.09 & 2.43 & $1-8$ & 3.33 & 2.14 & $0.5-8$ & 3.7 & 2.26 & $0.5-8$ \\
\hline Computer use experience (year) & 9.09 & 2.51 & $4-13$ & 8.37 & 3.76 & $1.5-15$ & 8.72 & 3.17 & $1.5-15$ \\
\hline
\end{tabular}

${ }^{\mathrm{a}}$ Mean. ${ }^{\mathrm{b}}$ Standard deviation.

Table 2

Mean and standard deviation of postural angle measured in sagittal plane while using different data entry devices $(n=23)$

\begin{tabular}{|c|c|c|c|c|c|c|c|}
\hline \multirow[t]{3}{*}{ Postural angles $\left(^{\circ}\right)$} & \multicolumn{6}{|c|}{ Data entry devices } & \multirow[t]{3}{*}{$P$-value } \\
\hline & \multicolumn{2}{|c|}{ Touch pad } & \multicolumn{2}{|c|}{ Touch screen } & \multicolumn{2}{|c|}{ Mouse } & \\
\hline & $\mathrm{M}^{\mathrm{a}}$ & $\mathrm{SD}^{\mathrm{b}}$ & $\mathrm{M}^{\mathrm{a}}$ & $\mathrm{SD}^{\mathrm{b}}$ & $\mathrm{M}^{\mathrm{a}}$ & $\mathrm{SD}^{\mathrm{b}}$ & \\
\hline Head inclination & -6.85 & 6.18 & -6.83 & 5.7 & -6.44 & 6.45 & 0.898 \\
\hline Neck inclination & 7.49 & 5.87 & 11.21 & 3.56 & 7.64 & 3.87 & $0.005^{\mathrm{c}}$ \\
\hline Trunk inclination & -5.67 & 6.71 & -13.44 & 8.64 & -4.73 & 6.87 & $<0.001^{\mathrm{c}}$ \\
\hline Arm angle & 10.88 & 9.46 & 21.01 & 14.98 & 9.27 & 11.73 & $<0.001^{\mathrm{c}}$ \\
\hline Elbow angle & -4.49 & 11.05 & 12.68 & 15.75 & 11.83 & 16.45 & $<0.001^{\mathrm{c}}$ \\
\hline
\end{tabular}

${ }^{\mathrm{a}}$ Mean. ${ }^{\mathrm{b}}$ Standard deviation. ${ }^{\mathrm{c}}$ ANOVA for repeated measures. 
- Head inclination (HI): Analysis of variance revealed that there was no statistically significant difference in head inclination when using the three types of input devices.

- Neck inclination (NI): Analysis of variance showed that the type of input device had a significant effect on neck inclination $(p=0.005)$. Touch screen resulted in more deviated neck posture than the two other input devices. As illustrated in Table 3, pairwise comparison indicated that neck inclination differed significantly between touch screen and touch pad $(p=0.01)$ as well as between touch screen and mouse $(p<0.001)$. Regarding this, there was no significant difference between mouse and touch pad.

- Trunk inclination (TI): Analysis of variance showed that the type of input device had a significant effect on trunk inclination $(p<0.001)$. Touch screen led to a more deviated trunk posture than the two other input devices. As illustrated in Table 3, pair wise comparison showed that trunk inclination differed significantly between touch screen and touch pad $(p<0.001)$ as well as between touch screen and mouse $(p<0.001)$. In this regards, no significant difference was found between mouse and touch pad.

- Arm angle (AA): Analysis of variance showed that the type of input device had a significant effect on arm angle $(p<0.001)$. Touch screen resulted in a more deviated arm posture than the two other input devices. As illustrated in Table 3, pairwise comparison indicated that arm angle differed significantly between touch screen and touch pad $(p=0.002)$ as well as between touch screen and mouse $(p=0.001)$. No significant difference was found between mouse and touch pad.

- Elbow angle (EA): Analysis of variance showed that the type of input device had a significant effect on elbow angle $(p<0.001)$. Touch screen and mouse led to a more deviated elbow posture than touch pad. As shown in Table 3, pairwise comparison indicated that elbow angle differed significantly between touch screen and touch pad $(p<0.001)$ as well as mouse and touch pad $(p<0.001)$. Regarding this, no significant difference was found between touch screen and mouse.

\subsection{Localized postural discomfort}

Table 4 presents the results of postural discomfort in the 5 body regions and the whole body in all three trials. Table 5 presents the results of pairwise comparisons between the 3 input devices.

- Neck and back: Analysis of variance showed that the type of input device had no significant effect on neck and back postural discomfort $(p>0.05)$.

Table 3

Pairwise comparison of postural angles between data entry devices $(n=23)$

\begin{tabular}{|c|c|c|c|c|c|c|c|c|c|c|c|c|c|}
\hline \multirow[t]{3}{*}{ Data entry devices } & & \multicolumn{12}{|c|}{ Postural angles $\left({ }^{\circ}\right)$} \\
\hline & & \multicolumn{3}{|c|}{ Neck inclination } & \multicolumn{3}{|c|}{ Trunk inclination } & \multicolumn{3}{|c|}{ Arm angle } & \multicolumn{3}{|c|}{ Elbow angle } \\
\hline & & $\mathrm{M}^{\mathrm{a}}$ & $\mathrm{SD}^{\mathrm{b}}$ & $P$-value & $\mathrm{M}^{\mathrm{a}}$ & $\mathrm{SD}^{\mathrm{b}}$ & $P$-value & $\mathrm{M}^{\mathrm{a}}$ & $\mathrm{SD}^{\mathrm{b}}$ & $P$-value & $\mathrm{M}^{\mathrm{a}}$ & $\mathrm{SD}^{\mathrm{b}}$ & $P$-value \\
\hline Touch pad & Touch screen & -3.72 & 1.31 & $0.01^{\mathrm{c}}$ & 7.8 & 1.8 & $<0.001^{\mathrm{c}}$ & -10.1 & 2.9 & $0.002^{\mathrm{c}}$ & -17.2 & 4.09 & $<0.001^{\mathrm{c}}$ \\
\hline Touch screen & Mouse & 3.57 & 0.8 & $<0.001^{\mathrm{c}}$ & -8.7 & 1.7 & $<0.001^{\mathrm{c}}$ & 11.7 & 3.12 & $0.001^{\mathrm{c}}$ & 0.86 & 4.4 & 0.85 \\
\hline Mouse & Touch pad & 0.14 & 1.18 & 0.9 & 0.94 & 1.3 & 0.48 & -1.61 & 2.01 & 0.43 & 16.3 & 3.04 & $<0.001^{\mathrm{c}}$ \\
\hline
\end{tabular}

${ }^{\mathrm{a}}$ Mean difference. ${ }^{\mathrm{b}}$ Standard deviation. ${ }^{\mathrm{c}}$ Pairwise comparison.

Table 4

Postural discomfort of different body regions as well as of the whole body in the three trials $(n=23)$. (Scale: $0=$ no discomfort, $9=$ very severe discomfort)

\begin{tabular}{|c|c|c|c|c|c|c|c|}
\hline \multirow[t]{3}{*}{ Body region } & \multicolumn{6}{|c|}{ Data entry devices } & \multirow[t]{3}{*}{$P$-value } \\
\hline & \multicolumn{2}{|c|}{ Touch pad } & \multicolumn{2}{|c|}{ Touch screen } & \multicolumn{2}{|c|}{ Mouse } & \\
\hline & $\mathrm{M}^{\mathrm{a}}$ & $\mathrm{SD}^{\mathrm{b}}$ & $\mathrm{M}^{\mathrm{a}}$ & $\mathrm{SD}^{\mathrm{b}}$ & $\mathrm{M}^{\mathrm{a}}$ & $\mathrm{SD}^{\mathrm{b}}$ & \\
\hline Neck & 1.46 & 2.14 & 1.41 & 2.11 & 1.46 & 2.15 & 0.981 \\
\hline Back & 1.11 & 1.54 & 1.36 & 1.97 & 0.75 & 1.32 & 0.116 \\
\hline Right shoulder & 1.3 & 1.72 & 1.89 & 2.46 & 0.77 & 1.1 & $0.017^{\mathrm{c}}$ \\
\hline Right elbow & 1.36 & 1.91 & 1.64 & 2.49 & 0.59 & 0.89 & $0.031^{\mathrm{c}}$ \\
\hline Right wrist/hand & 1.43 & 1.83 & 1.85 & 2.45 & 0.78 & 1.39 & $0.004^{\mathrm{c}}$ \\
\hline Whole body & 1.33 & 1.66 & 1.63 & 1.85 & 0.87 & 1.14 & $0.026^{\mathrm{c}}$ \\
\hline
\end{tabular}

${ }^{\mathrm{a}}$ Mean. ${ }^{\mathrm{b}}$ Standard deviation. ${ }^{\mathrm{c}}$ ANOVA for repeated measures. 
- Right shoulder: Analysis of variance indicated that the type of input device had a significant effect on right shoulder postural discomfort $(p=0.017)$. The lowest and the highest discomfort were reported while using mouse and touch screen, respectively. As presented in Table 5, pairwise comparison showed that right shoulder postural discomfort was significantly higher while using touch screen when compared to that of mouse $(p=0.01)$. Thus, no significant difference was found between touch screen and touch pad as well as between mouse and touch pad.

- Right elbow: Analysis of variance revealed that the type of input device had a significant effect on right elbow postural discomfort $(p=0.031)$. The lowest and highest discomfort were reported through the use of mouse and touch screen, respectively. As shown in Table 5, pair wise comparison indicated that right elbow postural discomfort was significantly higher while using touch screen as compared to those of mouse $(p=0.028)$ and touch pad $(p=0.03)$. In this regard, no significant difference was observed between touch screen and touch pad.

- Right wrist/hand: Analysis of variance showed that the type of input device had a significant effect on right wrist/hand postural discomfort $(p=0.004)$. The lowest and the highest discomfort were reported while using mouse and touch screen, respectively. As illustrated in Table 5, pairwise comparison indicated that right wrist/hand postural discomfort was significantly higher while using touch screen when compared to those of mouse $(p=0.004)$ and touch pad $(p=0.03)$. In this regard, no significant difference was found between touch screen and touch pad.

- Whole body: Analysis of variance indicated that the type of input device had a significant effect on whole body postural discomfort $(p=0.026)$. The lowest and the highest discomfort were reported while using mouse and touch screen, respectively. As indicated in Table 5, pairwise comparison showed that whole body postural discomfort was significantly higher while using touch screen when compared to that of touch $\operatorname{pad}(p=0.01)$. In this regard, no significant difference was found between touch screen and mouse, as well as between mouse and touch pad.

\subsection{Perceived posture}

Table 6 shows mean ratings for perceived posture of neck, back, right shoulder and right elbow in the three trials. Table 7 presents the results of pairwise comparisons between the 3 input devices.

The Friedman test revealed that the type of input device had no significant effect on neck and back perceived posture. The Friedman test showed that difference of mean ratings for perceived shoulder and elbow postures in the 3 trials were significant ( $p=0.005$ and $p=0.011$, respectively). Touch screen was reported to be the most unfavorable input device

Table 5

Pairwise comparison of postural discomfort between data entry devices $(n=23)$

\begin{tabular}{|c|c|c|c|c|c|c|c|c|c|c|c|c|c|}
\hline \multirow[t]{3}{*}{ Data entry devices } & & \multicolumn{12}{|c|}{ Body region } \\
\hline & & \multicolumn{3}{|c|}{ Right shoulder } & \multicolumn{3}{|c|}{ Right elbow } & \multicolumn{3}{|c|}{ Right wrist/hand } & \multicolumn{3}{|c|}{ Whole body } \\
\hline & & $\mathrm{M}^{\mathrm{a}}$ & $\mathrm{SD}^{\mathrm{b}}$ & $P$-value & $\mathrm{M}^{\mathrm{a}}$ & $\mathrm{SD}^{\mathrm{b}}$ & $P$-value & $\mathrm{M}^{\mathrm{a}}$ & $\mathrm{SD}^{\mathrm{b}}$ & $P$-value & $\mathrm{M}^{\mathrm{a}}$ & $\mathrm{SD}^{\mathrm{b}}$ & $P$-value \\
\hline Touch & Touch screen & -0.59 & 0.4 & 0.12 & -0.28 & 0.4 & 0.49 & -0.42 & 0.3 & 0.17 & -0.76 & 0.3 & $0.01^{\mathrm{c}}$ \\
\hline Touch screen & Mouse & 1.11 & 0.4 & $0.01^{\mathrm{c}}$ & 1.05 & 0.4 & $0.028^{\mathrm{c}}$ & 1.07 & 0.3 & $0.004^{\mathrm{c}}$ & 0.3 & 0.2 & 0.11 \\
\hline Mouse & Touch pad & -0.53 & 0.3 & 0.12 & -0.77 & 0.3 & $0.03^{\mathrm{c}}$ & -0.65 & 0.3 & $0.03^{\mathrm{c}}$ & 0.46 & 0.3 & 0.13 \\
\hline
\end{tabular}

${ }^{\mathrm{a}}$ Mean difference. ${ }^{\mathrm{b}}$ Standard deviation. ${ }^{\mathrm{c}}$ Pairwise comparison.

Table 6

Mean ratings for perceived posture of different body regions in the three trials $(n=23)$. (Scale: $1=$ very favorable, $3=$ favorable, $5=$ unfavorable, $7=$ very unfavorable)

\begin{tabular}{|c|c|c|c|c|c|c|c|}
\hline \multirow[t]{3}{*}{ Perceived posture } & \multicolumn{6}{|c|}{ Data entry devices } & \multirow[t]{3}{*}{$P$-value } \\
\hline & \multicolumn{2}{|c|}{ Touch pad } & \multicolumn{2}{|c|}{ Touch screen } & \multicolumn{2}{|c|}{ Mouse } & \\
\hline & $\mathrm{MR}^{\mathrm{a}}$ & $\mathrm{SD}^{\mathrm{b}}$ & $\mathrm{MR}^{\mathrm{a}}$ & $\mathrm{SD}^{\mathrm{b}}$ & $\overline{\mathrm{MR}^{\mathrm{a}}}$ & $\mathrm{SD}^{\mathrm{b}}$ & \\
\hline Neck & 1.93 & 1.28 & 2.22 & 1.16 & 1.85 & 1.38 & 0.132 \\
\hline Back & 1.96 & 1.00 & 2.26 & 1.34 & 1.78 & 1.08 & 0.088 \\
\hline Right shoulder & 1.87 & 1.27 & 2.46 & 1.41 & 1.67 & 1.34 & $0.005^{\mathrm{c}}$ \\
\hline Right elbow & 1.98 & 1.4 & 2.37 & 1.6 & 1.65 & 1.42 & $0.011^{\mathrm{c}}$ \\
\hline
\end{tabular}

${ }^{\mathrm{a}}$ Mean Rank. ${ }^{\mathrm{b}}$ Standard deviation. ${ }^{\mathrm{c}}$ Friedman test. 
Table 7

Pairwise comparison of perceived posture between data entry devices $(n=23)$

\begin{tabular}{|c|c|c|c|c|c|}
\hline \multirow[t]{3}{*}{ Data entry device } & & \multicolumn{4}{|c|}{ Perceived posture } \\
\hline & & \multicolumn{2}{|c|}{ Right shoulder } & \multicolumn{2}{|c|}{ Right elbow } \\
\hline & & $\mathrm{MR}^{\mathrm{a}}$ & $P$-value & $\mathrm{MR}^{\mathrm{a}}$ & $P$-value \\
\hline \multirow[t]{2}{*}{ Touch pad } & Touch screen & -2.28 & $0.022^{c}$ & -1.71 & 0.08 \\
\hline & Mouse & -0.94 & 0.35 & -2.07 & $0.038^{\mathrm{c}}$ \\
\hline Touch screen & Mouse & -2.88 & $0.004^{\mathrm{c}}$ & -2.94 & $0.003^{c}$ \\
\hline
\end{tabular}

${ }^{\mathrm{a}}$ Mean Rank difference. ${ }^{\mathrm{c}}$ Wilcoxon test.

based on the subjects' judgment. As illustrated in Table 7, Wilcoxon test indicated that difference of right shoulder mean rating was significant between touch pad and touch screen $(p=0.022)$ as well as between touch screen and mouse $(p=0.004)$. In this regard, no significant difference was found between touch pad and mouse. In addition, difference of right elbow mean rating was significant between touch pad and mouse $(p=0.038)$ as well as between touch screen and mouse $(p=0.003)$. In this regard, no significant difference was found between touch pad and touch screen.

\section{Discussion}

This study has resulted in a more detailed knowledge on the users' posture and discomfort while utilizing touch screen when compared to two other data entry devices. In the following paragraphs, significant results are particularly discussed.

\subsection{Postural variables}

The remarkable finding of this part is that different data entry devices induce significantly different neck, trunk and arm postures. Table 2 demonstrates the effects of data entry devices on postural variables except for the head. Among three devices, when touch screen is utilized, neck, trunk and arm get more deviation from neutral posture. This is in line with the results of other studies [1, 5, 9, 25-28]. The arm is extended significantly more in so as to perform tasks in the touch screen device. This finding is similar to other study results [6, 26-31]. Our observations showed that touch pad caused more deviated elbow posture. This is in agreement with the findings of Lin et al. study [29]. As the body is a kinematic linkage, the position of hands determines the posture of arm, elbow and trunk. Among data entry devices, mouse is an appropriate compromise device in which the postures of the neck, trunk, arm and elbow do not seem to be severely deviated from neutral posture [27].

Regarding various data entry devices, as touch screen leads to more inclined neck, trunk and not proper arm posture, the common usage of this device nowadays, is not recommended. However, mouse can be recommended as it is comfortable and affect positively body posture in comparison with the two other devices [27].

\subsection{Localized postural discomfort}

Among the data entry devices studied, touch screen resulted in higher right shoulder, elbow, wrist/hand and whole body discomfort as compared with the two other devices. This was in line with the results of previous studies in which touch screen use was reported to cause right elbow and wrist/hand high discomfort $[6,26,27,29]$.

\subsection{Perceived posture}

The results on perceived posture demonstrated that mouse significantly result in a more favored posture in shoulders and elbows. Touch screen is the most unfavorable data entry device based on the subjects' judgment.

\subsection{Limitations}

There were some limitations in this investigation. In this study, short term effects of working with 3 different types of input devises were investigated ( 15 min trials). The results of the trials may by different in longer experiment time (8). More reliable results are likely to be achieved by expanding the duration of each experimental session. Additionally, the postural angles were calculated in the first, middle and the last minutes of each trial. While the subjects' posture variations in the pre-defined tasks were limited, but if it were feasible to measure postural angles all through the $15 \mathrm{~min}$ trial, more conclusive 
results might be obtained. Moreover, increasing the number of test subjects may lead to clearer results. Besides that, the task was artificial (typical click and pointing task). Therefore, the results can only be assumed to be valid for this kind of computer task. Finally, if it were possible to record EMG data simultaneously, more reliable conclusions might be drawn.

\section{Conclusion}

The results revealed that among three devices, touch screen caused more deviated neck, trunk and arm postures. Additionally, body discomfort assessment demonstrated that touch screen resulted in higher shoulder, elbow, wrist/hand and whole body discomfort as compared with the two other devices. Furthermore, the findings on perceived posture indicated that touch screen was the most unfavorable data entry device based on the subjects' judgment.

Given the above, as a conclusion, it can be collectively declared that the use of touch screen deteriorates working postures of different body regions and increases user's discomfort. Therefore, it cannot be a preferred data entry device.

\section{Acknowledgments}

This article was extracted from a thesis written by Miss Najmeh Kargar, a M.Sc. student of Ergonomics and was financially supported by Shiraz University of Medical Sciences grant No. 92-6761. The authors wish to thank all students who participated in this study.

All the research considered the ethical guidelines, including adherence to the legal requirements of the study country. The manuscript has been submitted solely to this journal. All authors have read and approved the submitted version of the manuscript and that appropriate credit has been given to all contributors to this research. Credit to authorship is only to those that have participated substantially in the research work and preparation of this manuscript.

\section{Conflict of interest}

None to report.

\section{References}

[1] Jonai H, Beatriz M, Takata A, Sotoyama M, Saito S. Effects of the liquid crystal display tilt angle of a notebook computer on posture, muscle activities and somatic complaints. International Journal of Industrial Ergonomics. 2002(29):219-29.

[2] Bruno Garza JL, Young JG. A litrature review of the effects of computer input device design on biomechanical loading and muskuloskeletal outcomes during computer work. Work. 2015;52(2):217-30.

[3] Dundar H, Akcayir M. Tablet vs. Paper: The Effect on Learners'Reading Performance. International Electronic Journal of Elementary Education. 2012;4(3):441-50.

[4] Sundelin G, Hagberg M. Effects of exposure to excessive drafts on myoelectric activity in shoulder muscles. Journal of Electromechanical Kinesiol. 1992;2:36-41.

[5] Shin G, Zhu X. User discomfort, work posture and muscle activity while using a touchscreen in a desktop PC setting. Ergonomics. 2011;54(8):733-44.

[6] Karlqvist L, Bernmark E, Ekenvall L, Hagberg M, Isaksson A, Rosto T. Computer mouse and track-ball operation Similarities and differences in posture, muscular load and perceived exertion. International Journal of Industrial Ergonomics. 1999(23):157-69.

[7] Shin G, Zhu X. Ergonomic issues associated with the use of touchscreen desktop PC. Proceedings of the Human Factors and Ergonomics Society Annual Meeting. 2011;55: 949-53.

[8] Gustafsson E, Thom S, Grimby-Ekman A, Hagberg M. Texting on mobile phones and musculoskeletal disorders in young adults: A five-year cohort study. Applied Ergonomics. 2017;58:208-14.

[9] Young J, Trudeau M, Odell D, Marinelli K, Dennerlein J. Touchscreen tablet user configurations and case-supported tilt affect head and neck flexion angles. Work. 2012;41: 81-91

[10] World Medical A. World Medical Association Declaration of Helsinki. Ethical principles for medical research involving human subjects. Bulletin of the World Health Organization. 2008;59

[11] Delleman NJ. Visual determinants of working posture In: Karwowski W, Marras WS, editors. Computer applications in ergonomics, occupational safety and health. North-Holland: Elsevier Science Publishers B.V; 1992.

[12] Ankrum DR, Nemeth KJ, editors. Head and neck posture at computer workstations- what's neutral? Proceeding of the IEA; 2000.

[13] Bhatnager VDCG, Schiro SG. Posture, postural discomfort and performance. Human Factors. 1985;27:189-99.

[14] Marek T, Noworol C. The influence of under- and overstimulation on sitting posture. In: Corlett EN, Wilson J, Manenica I, editors. The ergonomics of working posture: Models, methods and cases. London: Taylor \& Francis; 1986.

[15] Aaras A, Westgaard RH, Stranden E. Postural angles as an indicator of postural load and muscular injury in occupational work situations. Ergonomics. 1988;31(6):915-33.

[16] Sauter SL, Schleifer LM. Work posture, workstation design, and musculoskeletal discomfort in a VDT data entry task. Human Factors. 1991;33(2):151-67.

[17] Li G, Haslegrave CM, Corlett EN. Factors affecting posture for machine sewing tasks. Applied Ergonomics. 1995;26(1):35-46. 
[18] Hunting W, Laubli TH, Grandjean E. Postural and visual loads at VDT workplaces: I. Constrained postures. Ergonomics. 1981;24(12):917-31.

[19] Grandjean M, Hunting W, Pidermann M. VDT workstation design: Preferred settings and their effects. Human Factors. 1983;25(2):161-75.

[20] Wrigley TV, Green RA, Briggs CA. Microcomputer video image processing technology in working posture analysis. Applied Ergonomics. 1991;22(1):2-8.

[21] Corlett EN, Bishop RP. A technique for assessing postural discomfort. Ergonomics. 1976;19(2):175-82.

[22] Delleman NJ. Working postures, prediction and evaluation. the Netherlands: TNO Human Factors Research Institute; 1999.

[23] Wayne WD. Applied nonparametric statistics. 5 nd ed. Duxbury: Duxbury classical series; 1990.

[24] Siegel S, Castellan NJ. Non-parametric statistics for the behavioral sciences. New York: McGraw-Hill; 75-83, 2003.

[25] Toy K, Peres S, David T, Nery A, Phillips R. Examining User Preferences in Interacting with Touchscreen Devices. Proceedings of the Human Factors and Ergonomics Society Annual Meeting. 2012;56:1862-6.

[26] Cook C, Burgess-Limerick R, Chang S. The prevalence of neck and upper extremity musculoskeletal symptoms in computer mouse users. International Journal of Industrial Ergonomics. 2000;26:347-56.

[27] Choobineh A, Lahmi M, Hosseini M, Shahnavaz H, Khani Jazani R. Workstation Design in Carpet Hand-Weaving Operation: Guidelines for Prevention of Musculoskeletal Disorders. JOSE. 2004;10(4):411-24.

[28] Xiea Y, Szeto GPY, Dai J, Madeleine P. A comparison of muscle activity in using touchscreen smartphone among young people with and without chronic neck-shoulder pain. Ergonomics. 2016;59(1):61-72.

[29] Lin MYC, Young JG, Dennerlein JT. Evaluating the effect of four different pointing device designs on upper extremity posture and muscle activity during mousing tasks. Applied Ergonomics. 2015;47:259-64.

[30] Atkinson SW, Haslam R, Buckle P. Using non-keyboard input devices: Interviews with users in the workplace. International Journal of Industrial Ergonomics. 2004(33):571-9.

[31] Conte C, Ranavolo A, Serrao M, Silvetti A, Orengo $\mathrm{G}$, Mari S, et al. Kinematic and electromyographic differences between mouse and touchpad use on laptop computers. International Journal of Industrial Ergonomics. 2014;44:413-20. 